of symptoms of synovial disease in many cases despite symptomatic improvement after synovectomy.

Though speakers at the conference emphasized early synovectomy, S. Vainio, ${ }^{3}$ of Finland, one of the most experienced surgeons in the management of rheumatoid disease, showed that in only 12 out of 201 cases in which he performed synovectomy on the knee could the disease be considered early in that no erosions were found at operation and radiography showed only para-articular atrophy and soft-tissue swelling. R. M. Mason ${ }^{4}$ at the same conference gave some interesting figures from the London Hospital. Of 53 knees subjected to synovectomy in the previous five years results were classed as good in 39 and bad in 9, the patient's assessment of pain as improved in 40 and worse in 8 . Asked if, in the light of their knowledge of the operation, they would have it again, 41 patients said yes, 12 no. Long duration of the disease in the joint, strongly positive tests for rheumatoid factor in the serum, and severe radiological changes all counted against a successful outcome. No changes were noted in sedimentation rates or latex titre after operation to suggest that it had any general effect on the disease process.

Two important articles have recently appeared from Denver, Colorado. In a historical review of synovectomy and débridement of the knee in rheumatoid arthritis, S. Geens ${ }^{5}$ examines the question of recurrence, the key point in this subject. In 13 series of patients with follow-up periods averaging 3 months to 6 years the incidence of recurrence ranged from zero to $54 \%$. Persistent postoperative hydrarthrosis was common. Geens concludes that synovectomy should be done "during the synovial phase of the disease," when radiographs show normal or almost normal joint spaces. But the malignant type of rheumatoid arthritis with multiple and progressive joint disease often gives poor results. He points out that the long-term effect of early versus delayed mobilization remains to be determined, and considers that the beneficial effect which synovectomy is reported to have on the patient's general condition and on the inflammatory state of the other joints has yet to be substantiated.

The second paper, by Geens and his colleagues, ${ }^{6}$ reports the end results of 31 operations for synovectomy and débridement on 23 patients - 3 children and 20 adults-between December 1959 and October 1966. All the adults had classic rheumatoid arthritis with multiple joint disease. In all but two the disease had run a progressive, active course. Most of them were advanced rather than early cases. Initial improvement followed operation in $79 \%$ of knees as assessed by the patient, and in $65 \%$ as assessed by the examiner, but definite or probable recurrence was noted in $46 \%$.

It is clear from this study that late synovectomy does not prevent progression of disease and that an initial improvement may go on to deterioration within a few years. A knee with instability and joint narrowing, as these authors point out, needs more than simple synovectomy. But the essential question-For how long does early synovectomy protect a

1 Paradies, L. H., in Symposium on Early Synovectomy in Rheumatoid Arthritis, 1967, 1969, ed. W. Hijmans, W. D. Paul, and H. Herschel. Amsterdam, Excerpta Medica.

2 London, P. S., Fournal of Bone and foint Surgery, 1955, 37B, 392.

Vainio, S., in Symposium on Early Synovectomy in Rheumatoid Arthritis, 1967, 1969, ed. W. Hijmans, W. D. Paul, and H. Herschel. Amsterdam, Excerpta Medica.

- Mason, R. M., in Symposium on Early Synovectomy in Rheumatoid Arthritis, 1967, 1969, ed. W. Hijmans, W. D. Paul, and H. Herschel.

: Geens, S., Fournal of Bone and foint Surgery, 1969, 51A, 617.

Geens, S., Clayton, M. L., Leidhodd, J. D., Smyth, C. J., and Bartholomew, B. A., Fournal of Bone and Foint Surgery, 1969, 51A, 626.

' Gariépy, R., Demers, R., and Laurin, C. A., Canadian Medical Association fournal, 1966, 94, 1349. joint ?-remains unanswered. Adequate long-term results are still awaited. Even among early cases in the best hands recurrences still occur. ${ }^{7}$ Furthermore, Geens and his colleagues showed that the earlier synovectomy is done the less is the subjective benefit for the patient. Spontaneous regressions or complete remissions are frequent in the early stages of rheumatoid disease, and if all such cases came to surgery many unnecessary operations would be performed.

Controlled clinical trials are now in progress in Britain and the U.S.A. Until we learn more from them it is as well to bear in mind that we do not yet, know much about progress and remission in individual joints attacked by rheumatoid arthritis. Four or five years is a short time in the life of a patient with rheumatoid arthritis. Total and complete synovectomy is not possible in the knee or any other joint. Therefore in all probability the longer the follow-up period the higher will be the relapse rate. In a disease with such a large number of variables careful analysis of long-term results in adequate groups of similar cases treated and untreated by synovectomy will be needed before proper judgement on the value of this operation can be given.

\section{Tortoises, Terrapins, and Turtles}

Any discussion of the occurrence of Salmonella spp. in reptiles is likely to be confused by popular nomenclature. The terrestrial vegetarians (Testudo spp.) which we in Britain call tortoises are "turtles" in the U.S.A., while the aquatic carnivores (Emys, Pseudemys), often called water tortoises, are now commonly known as terrapins in both countries. Both are kept as pets, and both have been responsible for salmonella infections in man. About $85 \%$ of imported tortoises harbour salmonellas in their bowels, and the figure for terrapins is not much lower but varies more between one batch and another.

Tortoises are caught wild in Morocco or Yugoslavia. They are naturally coprophagic, and once infected they may harbour the organisms for years without suffering any apparent ill-health. Most of the terrapins which reach the trade have been -reared artificially in terrapin farms in the southern U.S.A., where they are fed on meat offal of all kinds, some of which has been shown to contain salmonellas. When awaiting sale in Britain they get scraps of meat and meal worms. How long the terrapins can harbour the organisms no one seems to know.

The danger to man from these sources cannot amount to much. We do not know how many terrapins are sold in Britain, but a few years ago it was calculated that 300,000 tortoises were imported each year. In contrast to this the total number of reported human infections derived from these reptiles in all parts of the world amounts to perhaps 100 from terrapins and less than 50 from tortoises. It is, however, characteristic of infections from both sources that they have been mostly of young children, as in a case recently reported from Doncaster. ${ }^{1}$

Tortoises are not cuddly, but the inquisitive child who explores their anatomy in detail is liable to pick up some salmonellas on his fingers. Furthermore, the tortoise who

1 Jephcott, A. E., Martin, D. R., and Stalker, R., fournal of Hygiene,

2 Cruickshank, J. C., and Smith, H. W., British Medical fournal, 1949, 2, 1254 
basks on the lawn is likely to leave his faeces there and a child may mistake one for a liquorice all-sort. The danger from terrapins may be greater. Most are kept in aquaria indoors, and if the animals happen to be infected the water will be contaminated. No one is likely to drink aquarium water except, perhaps, dogs and other pets ; but it must be changed from time to time, and the obvious place for its disposal is the kitchen sink. He is a handy man who can do this without splashing, and he would certainly contaminate his hands.

Though the danger to health from these animals is a minor one, children must be protected as far as possible from the consequences of their own foolishness. There are reasons for forbidding the importation of tortoises, but these are based on arguments for the preservation of wild life rather than on health: in parts of Yugoslavia T. hermanni has become rare. Similar arguments cannot be advanced for terrapins since they are bred for the trade. It might be possible to treat all animals with an antibiotic before sale, but the cost would be high and, from the experience of a few trials, the outcome unsatisfactory. It is probably wiser to make it generally known that these animals are a potential source of disease; that they should not be handled more than is necessary; and that anyone who handles them should wash his hands. The aquarium water should not be brought into the kitchen but emptied down the lavatory or an outside drain. There is, however, little need to cry "wolf." Our dogs and cats share our lives far more intimately than do these reptiles, and at least $1 \%$ of them are carriers of salmonellas. ${ }^{2}$

\section{Switching Pills}

How urgent is the need for a woman taking an oral contraceptive to switch to one containing a low dose of oestrogen ? Despite statements made in the press and on television, there is no need for panic action. The right course for a woman is to continue to the end of her present cycle with the same pill (or even of another cycle to tide her over the New Year and the children's holidays) and to talk over the issue at leisure with her doctor. Some of the factors that should be considered are discussed in an article in Today's Drugs at p. 789.

Indiscriminate changing over from some of the higher-dose pills to the lower-dose pills carries some risk of pregnancy. What are these risks ? The Committee on Safety of Drugs has said in its circular No. 9 that it has no evidence that contraceptives containing $50 \mu \mathrm{g}$. of oestrogen are less effective than the others. This must be qualified, and the three types-the combined, the sequential, and the low-doseprogestogen-only pills-considered separately.

The committee's recommendations in fact exclude the use of sequential pills, since none of them contains as little as $50 \mu \mathrm{g}$. of oestrogen (in sequential therapy this is an ineffective dose for British women, giving a pregnancy rate of about 20 per 100 woman-years). Combined oral contraceptives containing $50 \mu \mathrm{g}$. of oestrogen are by no means comparable in potency, some being much more strongly progestogenic than others. Any patient transferred from one of the higher oestrogenic pills to Anovlar or
Gynovlar will run no risk of pregnancy in the transfer, because the progestogen in these is strong enough to exert a potent effect on the endometrium which will prevent pregnancy should ovulation occur with the drop in oestrogen dose. But transfer to one with a weak progestogenic effect would not give cover if break-through ovulation occurred. Such an ovulation could occur in the first week or two on the lower-dose oestrogen pills. Moreover, there is a real possibility that ovulation could be delayed and could occur in the first gap after medication or in the first few days of the second cycle. Thus for full safety other contraceptive precautions ought to be taken when changing over to any other of the low-dose pills for six weeks or so, and not for only the one week suggested by some manufacturers, or the two weeks suggested in their circular by the Family Planning Association. Combined pills are, however, fully effective when used for the first time by a woman of normal weight: it is the change-over from a high dose to a low dose of oestrogen which creates this problem.

The two new low-dose-progestogen-only pills (Normenon and Verton, both containing chlormadinone) are not suitable for women using oral contraceptives for maximum contraceptive effect, because pregnancies do occur-indeed the pregnancy rate in Britain based on trials in which every patient is followed up carefully is considerably higher than the rates quoted by the manufacturers based on huge transatlantic studies. Certainly any woman taking this type of pill is running some risk of pregnancy, whether she takes it from the beginning or transfers to it from a combined oral contraceptive.

The other difficulty facing doctors is related to the hormone balance of the pill. Oral contraceptives have been classified as predominantly oestrogenic, predominantly progestogenic, and intermediate in overall clinical effect, and it has been helpful to take into account a woman's own hormone balance and pre-existing menstrual complaints in finding a suitable pill to prescribe. Unfortunately all of the low-dose oestrogen pills are progestogenic in effect, and while they are probably the most useful category they are not suitable for all women. Side-effects such as gain in weight, leg cramps, and headache may occur in the early cycles, while depression and loss of libido may appear as long-term effects and require a change to a higher dose of oestrogen. Some women may find that the only pill they can tolerate is one with a high-oestrogen content, and if it is essential that they should avoid pregnancy this may still represent a. lesser overall risk.

\section{Syringomyelia and Cavities in the Cord}

The clinical diagnosis of syringomyelia relies on finding impairment of the sense of pain and temperature, preservation of the sense of touch and joint position (dissociated sensory loss), and diminished or absent tendon reflexes. These signs are normally present in both arms, and there may be signs of pyramidal disturbance and impairment of the sense of joint position in the legs. Pathologically there is cavitation-a syrinx-in the middle of the cord. 